\title{
The $\mathrm{CN} / \mathrm{C}^{15} \mathrm{~N}$ isotopic ratio towards dark clouds ${ }^{\star \star \star \star}$
}

\author{
P. Hily-Blant ${ }^{1}$, G. Pineau des Forêts ${ }^{2}$, A. Faure ${ }^{1}$, R. Le Gal ${ }^{1}$, and M. Padovani ${ }^{3}$ \\ ${ }^{1}$ Université Joseph Fourier and CNRS, Institut de Planétologie et d'Astrophysique, 38041 Grenoble, France \\ e-mail: Pierre.Hily-Blant@obs.ujf-grenoble.fr \\ ${ }^{2}$ Université Paris-Orsay and CNRS, Institut d'Astrophysique Spatiale, 91405 Orsay, France \\ 3 LRA/CNRS, Observatoire de Paris \& École normale supérieure, 75005 Paris, France
}

Received 26 February 2013 / Accepted 26 June 2013

\section{ABSTRACT}

\begin{abstract}
Understanding the origin of the composition of solar system cosmomaterials is a central question, not only in the cosmochemistry and astrochemistry fields, and requires various approaches to be combined. Measurements of isotopic ratios in cometary materials provide strong constraints on the content of the protosolar nebula. Their relation with the composition of the parental dark clouds is, however, still very elusive. In this paper, we bring new constraints based on the isotopic composition of nitrogen in dark clouds, with the aim of understanding the chemical processes that are responsible for the observed isotopic ratios. We have observed and detected the fundamental rotational transition of $\mathrm{C}^{15} \mathrm{~N}$ towards two starless dark clouds, L1544 and L1498. We were able to derive the column density ratio of $\mathrm{C}^{15} \mathrm{~N}$ over ${ }^{13} \mathrm{CN}$ towards the same clouds and obtain the $\mathrm{CN} / \mathrm{C}^{15} \mathrm{~N}$ isotopic ratios, which were found to be $500 \pm 75$ for both L1544 and L1498. These values are therefore marginally consistent with the protosolar value of 441. Moreover, this ratio is larger than the isotopic ratio of nitrogen measured in $\mathrm{HCN}$. In addition, we present model calculations of the chemical fractionation of nitrogen in dark clouds, which make it possible to understand how $\mathrm{CN}$ can be deprived of ${ }^{15} \mathrm{~N}$ and $\mathrm{HCN}$ can simultaneously be enriched in heavy nitrogen. The non-fractionation of $\mathrm{N}_{2} \mathrm{H}^{+}$, however, remains an open issue, and we propose some chemical way of alleviating the discrepancy between model predictions and the observed ratios.
\end{abstract}

Key words. ISM: abundances - ISM: clouds - ISM: general - ISM: molecules - astrochemistry

\section{Introduction}

Understanding the origin of the elements in the solar system is a crucial issue at the crossroads of astrophysics, cosmochemistry, and astrobiology. In this respect, comets play a particular role because they are considered the most ancient relics of the formation of the solar system from the protosolar nebula, $4.567 \mathrm{Gyr}$ ago. If it is certain that all cometary material has an interstellar origin, what is unclear is whether there is any chemical species present in e.g. cometary ices that have remained unaltered since their incorporation into those ices. The central issue is to determine the origin of the elements that are detected in comets and interplanetary dust particles and to unveil their chemical link with the pristine interstellar matter. The detection of glycine in 81P/Wild 2 cometary samples by Elsila et al. (2009) makes the question of the presence of glycine in the interstellar medium (ISM) still a crucial one. Direct analysis of interplanetary dust particles and meteorites provides clues to the composition of the solar system (e.g. Bonal et al. 2010), but due to their thermal and physical evolution since their formation, it is not always easy to trace the origins of the cosmomaterials back to the nascent protosolar system or even to the parental dark cloud. Isotopic composition may be a better tool in this respect. Isotopic ratios have proven extremely powerful in providing quantitative constraints on the composition of the protosolar disk from which the solar system formed (Chaussidon \& Gounelle 2007; Jehin et al. 2009). For carbon, the isotopic ratio ${ }^{12} \mathrm{C} /{ }^{13} \mathrm{C}$ measured in comets shows

\footnotetext{
* Appendices are available in electronic form at http://www . aanda.org

$\star \star$ The reduced spectra (in FITS format) are available at the CDS via anonymous ftp to cdsarc.u-strasbg. fr (130.79.128.5) or via http://cdsarc.u-strasbg.fr/viz-bin/qcat?]/A+A/557/A65
}

a remarkable homogeneity, with a mean value of 91 that agrees with the solar value of 90 and is also very close to the value of 70 determined in the local ISM (Milam et al. 2005; Asplund et al. 2009; Manfroid et al. 2009). For oxygen, measurements in comets lead to ${ }^{16} \mathrm{O} /{ }^{18} \mathrm{O}$ ratios between 500 and 600 , which again are in good agreement with the solar and local ISM value of 500 (Wilson \& Rood 1994).

However, for nitrogen, which is the next most abundant element, measurements in various environments, such as the Sun, the solar system, and the ISM, draw a much more contrasted picture. The Genesis mission has recently allowed Marty et al. (2011) to measure the nitrogen isotopic ratio in the solar wind, yielding ${ }^{14} \mathrm{~N} /{ }^{15} \mathrm{~N}=441 \pm 5$ for the protosolar nebula. This value is significantly larger than the terrestrial value of 272 . A review of the ${ }^{14} \mathrm{~N} /{ }^{15} \mathrm{~N}$ measurements in primitive matter of the solar system (Mumma \& Charnley 2011) confirms the idea of a strongly variable ${ }^{14} \mathrm{~N} /{ }^{15} \mathrm{~N}$ ratio in the solar system. Observations of the ${ }^{14} \mathrm{~N} /{ }^{15} \mathrm{~N}$ ratio in protoplanetary disks may also be directly compared to the value from the Genesis mission. Unfortunately, measurements of isotopic ratios in the most evolved gas-poor disks like TW Hya (Kastner et al. 2010) are extremely difficult, except for carbon and oxygen-bearing molecular species (e.g. CO Dutrey et al. 1997, 2007), whose large abundances make their major isotopologues detectable. This is in contrast with cold and dense starless cores, where N-bearing molecules (HCN, HNC, $\mathrm{CN}, \mathrm{NH}_{3}, \mathrm{~N}_{2} \mathrm{H}^{+}$, NO) are routinely observed (Gerin et al. 1992; Crapsi et al. 2005, 2007; Hily-Blant et al. 2010b; Padovani et al. 2011), together with their ${ }^{15} \mathrm{~N}$ isotopologues (Ikeda et al. 2002; Gerin et al. 2009; Lis et al. 2010). The recent observation of $\mathrm{N}^{15} \mathrm{NH}^{+}$towards the starless core $\mathrm{L} 1544$ by Bizzocchi et al. (2010) leads to an isotopic ratio $\mathrm{N}_{2} \mathrm{H}^{+} / \mathrm{N}^{15} \mathrm{NH}^{+}=446 \pm 71$, a value equal to that of the protosolar nebula. Similar values were 
Table 1. Spectroscopic properties of the observed species and transitions.

\begin{tabular}{|c|c|c|c|c|c|c|}
\hline Molecule & $\begin{array}{c}B^{a} \\
\mathrm{MHz}\end{array}$ & $\begin{array}{c}\mu_{0}^{b} \\
\text { Debye }\end{array}$ & Transition $^{c}$ & $\begin{array}{c}\text { Frequency }^{d} \\
\mathrm{MHz}\end{array}$ & $\begin{array}{r}A_{u l}{ }^{e} \\
\mathrm{~s}^{-1} \\
\end{array}$ & $g_{u}^{f}$ \\
\hline${ }^{13} \mathrm{CN}$ & 54353.130 & 1.45 & $13 / 223 \rightarrow 01 / 212$ & 108780.201 & $1.05 \times 10^{-5}$ & 7 \\
\hline $\mathrm{C}^{15} \mathrm{~N}$ & 54958.510 & 1.45 & $\begin{array}{lllll}1 & 3 / 2 & 2 \rightarrow 0 & 1 / 2 & 1 \\
1 & 3 / 2 & 1 \rightarrow 0 & 1 / 2 & 0 \\
1 & 3 / 2 & 1 \rightarrow 0 & 1 / 2 & 1 \\
1 & 1 / 2 & 1 \rightarrow 0 & 1 / 2 & 1 \\
1 & 1 / 2 & 1 \rightarrow 0 & 1 / 2 & 0 \\
1 & 1 / 2 & 0 \rightarrow 0 & 1 / 2 & 1\end{array}$ & $\begin{array}{l}110024.590 \\
110023.540 \\
110004.092 \\
109689.610 \\
109708.986 \\
109733.657\end{array}$ & $\begin{array}{l}1.09 \times 10^{-5} \\
7.16 \times 10^{-6} \\
3.70 \times 10^{-6} \\
7.10 \times 10^{-6} \\
3.67 \times 10^{-6} \\
1.08 \times 10^{-5}\end{array}$ & $\begin{array}{l}5 \\
3 \\
3 \\
3 \\
3 \\
1\end{array}$ \\
\hline
\end{tabular}

Notes. ${ }^{(a)}$ Rotational constant. ${ }^{(b)}$ Dipole moment. ${ }^{(c)}$ For $\mathrm{C}^{15} \mathrm{~N}$, the quantum numbers are $N J F$ with $J=N+S$ and $F=J+I$, where $S$ is the electronic spin and $I=1 / 2$ is the nuclear spin of ${ }^{15} \mathrm{~N}$. For ${ }^{13} \mathrm{CN}$, we follow the CDMS convention (which differs from Bogey et al. 1984), where the quantum numbers are $N J F_{1} F$ with $F_{1}=J+I_{1}, F=F_{1}+I_{2}$ where $I_{1}=1 / 2$ and $I_{2}$ are the nuclear spin of ${ }^{13} \mathrm{C}$ and ${ }^{14} \mathrm{~N}$ respectively. ${ }^{(d)}$ For resolved hyperfine structures, frequency of a given hyperfine component. ${ }^{(e)}$ Einstein coefficient for spontaneous decay. ${ }^{(f)}$ Total degeneracy of the upper level.

obtained by Gerin et al. (2009) in other cold dense cores using $\mathrm{NH}_{2} \mathrm{D}$, though with much larger uncertainties. These values contrast with the HCN measurements by Ikeda et al. (2002) and Lucas \& Liszt (1998), who find ratios of 150 and 240 in dark and diffuse molecular gas respectively. More recently, Adande \& Ziurys (2012) found similar values based on HCN and CN observations towards warm $(T>25 \mathrm{~K})$ molecular clouds, with ratios from 150 to 350 . Even more recently, Hily-Blant et al. (2013, hereafter HB13) report HCN isotopic ratios between 140 and 360, where the range of values is shown to reflect genuine spatial variations of the ratio. HB13 also suggest that the large variations of the ${ }^{14} \mathrm{~N} /{ }^{15} \mathrm{~N}$ ratio in cosmomaterials, in dark clouds, and in the more diffuse ISM may indeed be rooted in the interstellar nitrogen chemistry. The underlying idea is that there are two reservoirs of interstellar nitrogen characterized by different isotopic ratios: nitrile carriers (such as $\mathrm{HCN}$ ) are systematically enriched in ${ }^{15} \mathrm{~N}$ with respect to the Sun's value, whereas hydrides (such as ammonia) show values encompassing that measured in the Sun. The differential fractionation of these two reservoirs may originate in the interstellar chemistry of nitrogen. This is because nitriles essentially derive from atomic nitrogen, whereas hydrides derive from molecular nitrogen.

Because atomic and molecular nitrogen, which are presumably the main reservoirs of nitrogen, are not directly observable in the dense ISM, the determination of the bulk ${ }^{14} \mathrm{~N} /{ }^{15} \mathrm{~N}$ is indirect and relies on the observation of minor N-bearing molecules. To which extent the abundance ratio of two isotopologues of a given molecule is representative of the elemental isotopic ratio depends on so-called fractionation processes: the stronger these processes, the larger the departure of the molecular abundance ratio from the elemental ratio. Fractionation processes are of two types: chemical and selective photodissociation effects. The latter effect can safely be ignored in dark clouds, which are dense and shielded regions. Chemical effects are potentially important in cold gas (Watson et al. 1976; Langer et al. 1984). Regarding nitrogen, Terzieva \& Herbst (2000, hereafter TH00) investigated chemical fractionation in dense and cold clouds $\left(n_{\mathrm{H}}=2 \times 10^{4} \mathrm{~cm}^{-3}, T=10 \mathrm{~K}\right)$, and found essentially no fractionation of any nitrogen-bearing molecule. This was further investigated by Charnley \& Rodgers (2002), who showed, in contrast, that in situations where $\mathrm{OH}$ is strongly depleted from the gas-phase, there is more atomic nitrogen available for fractionation. Indeed, large fractionation levels are predicted, e.g. for $\mathrm{NH}_{3}$, at early times in their calculations. However, these models also predict strong fractionation of $\mathrm{N}_{2} \mathrm{H}^{+}$, which is not observed. Therefore, none of the two available models of nitrogen fractionation in dark clouds are able to reproduce the observational constraints.

The $\mathrm{CN}$ radical plays a peculiar role in the nitrogen chemistry because it is a mediator of the atomic-to-molecular conversion (HB13). $\mathrm{CN}$ is also coupled with the dominant nitriles such as $\mathrm{HCN}$ and $\mathrm{HNC}$, which derive from atomic nitrogen. Thus, the nitrogen fractionation level of $\mathrm{CN}$ potentially provides interesting constraints on the fractionation pathways. In this paper, we report the detection of $\mathrm{C}^{15} \mathrm{~N}$ towards two starless cores, L1544 and L1498. Put in conjunction with the $\mathrm{N}_{2} \mathrm{H}^{+}$and $\mathrm{HCN}$ fractionation measurements available towards L1544, it is expected that these new observations will strongly constrain models.

The paper is structured as follows. In Sect. 2, we present the observations and column density derivation. In Sect. 3, we present our fractionation model, to which we compare the ${ }^{14} \mathrm{~N} /{ }^{15} \mathrm{~N}$ measured in $\mathrm{CN}$ and other molecules. The discussion is the subject of Sect. 4 .

\section{Observations}

The $N=1-0$ rotational spectrum of $\mathrm{C}^{15} \mathrm{~N}$ is split into fine and hyperfine structures, which arise from the electron spin and the $I=1 / 2$ nuclear spin of the ${ }^{15} \mathrm{~N}$ atom. There are two groups of lines due to the fine structure, which are distant by $300 \mathrm{MHz}$ (see Table 1). The strongest hyperfine component is the $(N, J, F)=$ $\left(1, \frac{3}{2}, 2\right) \rightarrow\left(0, \frac{1}{2}, 1\right)$ transition at $110024.590 \mathrm{MHz}$, with a relative intensity of 0.417 (Saleck et al. 1994). The next strongest transitions have relative intensities of $17 \%$, with frequencies of 109689.610 and $110023.540 \mathrm{MHz}$. All six hyperfine components were observed simultanously towards L1498 and L1544 at the IRAM 30m telescope in May $2012(\approx 16 \mathrm{~h}$ per source) under good weather conditions. The VESPA autocorrelator was used as a spectrometer to provide us with high-resolution spectra, namely, $20 \mathrm{kHz}$ or $0.054 \mathrm{~km} \mathrm{~s}^{-1}$ at $110 \mathrm{GHz}$. The typical receiver temperature achieved with the EMIR detectors (Carter et al. 2012) was $\approx 40 \mathrm{~K}$, resulting in system temperatures $\approx 120 \mathrm{~K}$. Amplitude calibration was performed using the threephase IRAM method typically every $10 \mathrm{~min}$. Pointing and focus sessions using strong continuum sources were repeated every one and two hours respectively. The wobbler-switching mode (140" throw) was used to provide us with high-quality baselines, such that residual bandpass calibration effects could be handled 
P. Hily-Blant et al.: The $\mathrm{CN} / \mathrm{C}^{15} \mathrm{~N}$ isotopic ratio towards dark clouds

Table 2. Line properties towards L1544 and L1498 and associated column density ratios from LVG calculations.

\begin{tabular}{|c|c|c|c|c|c|c|c|c|c|c|}
\hline \multirow[t]{2}{*}{ Source } & \multicolumn{4}{|c|}{${ }^{13} \mathrm{CN}^{a}$} & \multicolumn{4}{|c|}{$\mathrm{C}^{15} \mathrm{~N}^{a}$} & \multirow[t]{2}{*}{${ }^{13} \mathrm{CN} / \mathrm{C}^{15} \mathrm{~N}^{b}$} & \multirow[t]{2}{*}{$\mathrm{C}^{14} \mathrm{~N} / \mathrm{C}^{15} \mathrm{~N}^{c}$} \\
\hline & $\begin{array}{c}W \\
\mathrm{mK} \mathrm{km} \mathrm{s}^{-1} \\
\end{array}$ & $\begin{array}{c}T_{0} \\
\mathrm{mK} \\
\end{array}$ & $\begin{array}{c}v_{0} \\
\mathrm{~km} \mathrm{~s}^{-1} \\
\end{array}$ & $\begin{array}{c}F W H M \\
\mathrm{~km} \mathrm{~s}^{-1}\end{array}$ & $\begin{array}{c}W \\
\mathrm{mK} \mathrm{km} \mathrm{s}^{-1} \\
\end{array}$ & $\begin{array}{c}T_{0} \\
\mathrm{mK} \\
\end{array}$ & $\begin{array}{c}v_{0} \\
\mathrm{~km} \mathrm{~s}^{-1} \\
\end{array}$ & $\begin{array}{c}F W H M \\
\mathrm{~km} \mathrm{~s}^{-1}\end{array}$ & & \\
\hline L1498 & $28(2)$ & $114(14)$ & $7.84(0.01)$ & $0.23(0.02)$ & $6(1)$ & $34(7)$ & $7.73(0.02)$ & $0.17(0.03)$ & $7.0 \pm 1.0$ & $476 \pm 70$ \\
\hline L1544 & $73(4)$ & $166(15)$ & $7.17(0.02)$ & $0.44(0.03)$ & $20(2)$ & $47(10)$ & $7.18(0.03)$ & $0.40(0.05)$ & $7.5 \pm 1.0$ & $510 \pm 70$ \\
\hline
\end{tabular}

Notes. ${ }^{(a)}$ From Gaussian fits. Statistical uncertainties at the $1 \sigma$ are in parenthesis for a velocity resolution of $0.05 \mathrm{~km} \mathrm{~s}^{-1}$ at $110 \mathrm{GHz}{ }^{(b)}$ Adopting FWHM of 0.20 an $0.40 \mathrm{~km} \mathrm{~s}^{-1}$ for L1498 and L1544 respectively. Conservative uncertainties based on $\chi^{2}$ minimization. ${ }^{(c)}$ Adopting ${ }^{12} \mathrm{C} /{ }^{13} \mathrm{C}=68$ (Milam et al. 2005).

with first-order polynomial fitting. The $\mathrm{HC}^{15} \mathrm{~N}(1-0)$ data reported in this paper are taken from Hily-Blant et al. (2010b). The ${ }^{13} \mathrm{CN}(1-0)$ rotational spectrum also presents fine and hyperfine structures, which are described in Bogey et al. (1984). For the present analysis, we use only the brightest hyperfine component, at 108780.201 (Hily-Blant et al. 2008). The spectroscopic properties of both species and observed transitions are summarized in Table 1. Towards L1544, the ${ }^{13} \mathrm{CN}$ spectrum is taken from Hily-Blant et al. (2010b), and towards L1498, it is taken from unpublished spectra of Padovani et al. (2011). Data reduction was done using the CLASS software (Hily-Blant et al. 2005). All plots were done in the GILDAS environment provided by IRAM (Pety 2005). The J2000 coordinates for L1498 and L1544 are $\alpha, \delta=04: 10: 51.50,25: 09: 58.0$ and 05:04:16.90, 25:10:47.0 respectively.

\section{Results}

Among the three brightest $\mathrm{C}^{15} \mathrm{~N}$ lines, only the strongest, with a relative intensity of $42 \%$, is clearly detected towards both sources. The line properties, which are derived from Gaussian fits, are summarized in Table 2 . We also give the properties of the ${ }^{13} \mathrm{CN}(1-0)$ line obtained in a similar fashion. We note a $0.1 \mathrm{~km} \mathrm{~s}^{-1}$ discrepancy between the velocities of the ${ }^{13} \mathrm{CN}$ and $\mathrm{C}^{15} \mathrm{~N}$ lines towards L1498, which could not be ascribed to any obvious technical issue. We note, however, that the uncertainty on the rest frequency reported in the Cologne Database for Molecular Spectroscopy (Müller et al. 2005) is $0.1 \mathrm{MHz}$, or $0.25 \mathrm{~km} \mathrm{~s}^{-1}$, which could account for the observed shift. New observation of the ${ }^{13} \mathrm{CN}(1-0)$ towards L 1498 should be performed to check this discrepancy. We are, however, most confident that the detected lines are ${ }^{13} \mathrm{CN}$ and $\mathrm{C}^{15} \mathrm{~N}$, since we searched for other lines at those frequencies in public databases and could not find any likely candidate. There is a marginal detection of the $110023.540 \mathrm{MHz}$ line towards L1544, which has a peak intensity of $20 \mathrm{mK}$. This intensity well matches what would be expected from the relative intensities $(17 \%$ that of the strongest line), which suggests that the lines are optically thin. This secondary component is not detected towards L1498, though there is some emission at the expected velocity (within the $0.1 \mathrm{MHz}$ uncertainty), with an upper limit that is consistent with the relative intensities of these two components. The analysis below is based solely on the strongest $\mathrm{C}^{15} \mathrm{~N}$ line at $110024.590 \mathrm{MHz}$.

Line intensities towards L1544 are stronger than towards L1498 and are also broader by a factor $\approx 2$. This is likely due to the L1544 lines presenting two closeby velocity components (Hily-Blant et al. 2010b), which are not resolved in the $\mathrm{C}^{15} \mathrm{~N}$ spectrum. These two velocity components may be related to the collapse signature recently evidenced by the inverse P-Cygni profile of a water line (Caselli et al. 2012).
To derive column densities from the emission lines, we performed radiative transfer calculations with the RADEX code (van der Tak et al. 2007), using the large velocity gradient (LVG) approximation for an expanding sphere. The hyperfine rate coefficients for $\mathrm{C}^{15} \mathrm{~N}$ and ${ }^{13} \mathrm{CN}$ were derived from the rate coefficients computed by Kalugina et al. (2012) for $\mathrm{CN}+\mathrm{H}_{2}$ using the infinite-order-sudden approximation (see Appendix C). We assumed that the source has a constant density and temperature and that it uniformly fills the telescope beam. The line width was held fixed at $0.2 \mathrm{~km} \mathrm{~s}^{-1}$ for L1498 and at $0.4 \mathrm{~km} \mathrm{~s}^{-1}$ for L1544. The intensity of the observed ${ }^{13} \mathrm{CN}(1-0)$ transition was computed for varying ${ }^{13} \mathrm{CN}$ column density $\left(N\left({ }^{13} \mathrm{CN}\right)\right), \mathrm{H}_{2}$ density $\left(n_{\mathrm{H}_{2}}\right)$, and kinetic temperatures $(T)$. The kinetic temperatures considered span the range 7 to $12 \mathrm{~K}$ by steps of $1 \mathrm{~K}$. Figure B.1 shows the resulting line intensity for a kinetic temperature of $10 \mathrm{~K}$. A continuum range of solutions matches the observation constraints summarized in Table 2, with densities $n_{\mathrm{H}_{2}}=10^{4}$ to a few $10^{5} \mathrm{~cm}^{-3}$ and associated ${ }^{13} \mathrm{CN}$ column densities from $6 \times 10^{13}$ to $2.5 \times 10^{12} \mathrm{~cm}^{-2}$. Refined calculations were then performed across this range for both ${ }^{13} \mathrm{CN}$ and $\mathrm{C}^{15} \mathrm{~N}$. For $\mathrm{C}^{15} \mathrm{~N}$, a similar ensemble of solutions was found. Even though the density and column density are degenerate, the ${ }^{13} \mathrm{CN}$ and $\mathrm{C}^{15} \mathrm{~N}$ solutions are characterized by a constant ${ }^{13} \mathrm{CN} / \mathrm{C}^{15} \mathrm{~N}$ column density ratio across the full range of solutions. Finally, refined calculations were done in which the $\mathrm{C}^{15} \mathrm{~N}$ column density was such that $6 \leq N\left({ }^{13} \mathrm{CN}\right) / N\left(\mathrm{C}^{15} \mathrm{~N}\right) \leq 9$. The ${ }^{13} \mathrm{CN} / \mathrm{C}^{15} \mathrm{~N}$ column density ratios are 7.5 and 7 for L1544 and L1498 respectively. Although the density and column density are degenerate, equal excitation temperatures (within $0.1 \mathrm{~K}$ ) of $3-5 \mathrm{~K}$ are found for the ${ }^{13} \mathrm{CN}$ and $\mathrm{C}^{15} \mathrm{~N}$, across the full range of solutions. The ${ }^{13} \mathrm{CN}$ line is found to be only marginally thin, with an opacity close to unity, whilst the $\mathrm{C}^{15} \mathrm{~N}$ line can safely be assumed to be thin. It is of interest to note that LTE calculations using excitation temperatures in the range 3-4 K provide abundance ratios which agree reasonably well with the above LVG calculations.

On chemical grounds, both species follow similar formation and destruction routes and are thus expected to coexist spatially hence the above column density ratios are representative of their abundance ratios. If we now assume that ${ }^{12} \mathrm{CN} /{ }^{13} \mathrm{CN}={ }^{12} \mathrm{C} /{ }^{13} \mathrm{C}$ and adopt for the latter the value of 68 from Milam et al. (2005), we derive an isotopic ratio $\mathrm{CN} / \mathrm{C}^{15} \mathrm{~N}=476 \pm 70$ in $\mathrm{L} 1498$ and $\mathrm{CN} / \mathrm{C}^{15} \mathrm{~N}=510 \pm 70$ in L1544, where conservative uncertainties are applied (see Table 2). Altogehter, these values give $\mathrm{CN} / \mathrm{C}^{15} \mathrm{~N}=500 \pm 75$.

The ${ }^{13} \mathrm{CN}$ column density may also be compared with the $\mathrm{H}^{13} \mathrm{CN}$ column density, which is $1.8 \times 10^{12} \mathrm{~cm}^{-2}$ towards L1498 (Padovani et al. 2011) and $4.6 \times 10^{12} \mathrm{~cm}^{-2}$ towards L1544 (HB13). The ${ }^{13} \mathrm{CN}: \mathrm{H}^{13} \mathrm{CN}$ ratios are thus 0.6 and 1.7 for $\mathrm{L} 1498$ and L1544 respectively, which are in harmony with ratios found by Hily-Blant et al. (2010b) towards several starless cores. 


\section{Comparison to model predictions}

\subsection{Fractionation of nitriles and hydrides}

The $\mathrm{CN} / \mathrm{C}^{15} \mathrm{~N}$ abundance ratios inferred in the two starless cores are thus only slightly larger than the protosolar value of ${ }^{14} \mathrm{~N} /{ }^{15} \mathrm{~N}=441$, but significantly larger the $\mathrm{HCN} / \mathrm{HC}{ }^{15} \mathrm{~N}$ ratio derived by $\mathrm{HB} 13$ towards $\mathrm{L} 183$ and $\mathrm{L} 1544$, which are smaller than the protosolar ratio. In contrast, the $\mathrm{CN} / \mathrm{C}^{15} \mathrm{~N}$ ratio is similar to that measured in hydrides $\left(\mathrm{NH}_{3}, \mathrm{~N}_{2} \mathrm{H}^{+}\right)$towards dark clouds by Bizzocchi et al. (2010), Gerin et al. (2009), and Lis et al. (2010). At first glance, this is at odds with the suggestion that hydrides and nitriles present different fractionation degrees (HB13), because one would have expected $\mathrm{CN}$ to behave more like $\mathrm{HCN}$ than like $\mathrm{NH}_{3}$. Yet, it must be recognized that $\mathrm{CN}$ plays a particular role in the chemistry of nitrogen: though it is a nitrile, it reacts directly with $\mathrm{N}$ to form $\mathrm{N}_{2}$ from which hydrides derive. Hence, the non-fractionation of $\mathrm{CN}$ may not be in contradiction with the chemical picture proposed in by HB13.

\subsection{Model calculations}

We thus wish to understand how the $\mathrm{CN}$ radical gets deprived in ${ }^{15} \mathrm{~N}$ and at the same time HCN is enriched in ${ }^{15} \mathrm{~N}$. To this aim, we implemented the fractionation reactions of THOO into a dark cloud chemical network based on Flower \& Pineau des Forêts (2003), in which the nitrogen chemistry has been fully revised. The most important changes regard the dissociative recombinations of ions such as $\mathrm{NH}_{2}^{+}, \mathrm{NH}_{3}^{+}$, and $\mathrm{NH}_{4}^{+}$, which are critical for the production of hydrides. Following Dislaire et al. (2012), the dissociative recombination of $\mathrm{N}_{2} \mathrm{H}^{+}$possesses a channel producing NH with a branching ratio of $\approx 5 \%$ (Vigren et al. 2012). The gas phase ortho-to-para conversion of $\mathrm{H}_{2}$ through proton exchange reactions has also been fully updated (Rist et al. 2013, and references therein) since the rate of the key reaction $\mathrm{N}^{+}+\mathrm{H}_{2}$ depends critically on the ortho-to-para ratio of $\mathrm{H}_{2}$ (Dislaire et al. 2012). Other important reactions have been updated, based on the recent laboratory work of Daranlot et al. (2012). In a first approach, the updated chemical network of Le Gal was simplified by ignoring the ortho- and para- forms of $\mathrm{H}_{2}, \mathrm{H}_{3}^{+}$, and other nitrogen-bearing molecules. This means that the rate of the reaction $\mathrm{N}^{+}+\mathrm{H}_{2}$ was held fixed at a value corresponding to an ortho:para ratio of $\mathrm{H}_{2}$, of $10^{-3}$, in a similar fashion as in Dislaire et al. (2012).

The chemical fractionation reactions considered by THOO are ion-neutral reactions, because they are the fastest and are hence expected to be the most efficient. These reactions consist in forward and backward reactions,

$\mathrm{A}^{+}+\mathrm{B} \underset{k_{\mathrm{r}}}{\stackrel{k_{\mathrm{f}}}{\rightleftharpoons}} \mathrm{C}^{+}+\mathrm{D}+\Delta E$

where $\Delta E$ is the zero-point energy difference between the products and reactants, such that $\Delta E>0$ if the reaction is exothermic. The rates of the forward and backward reactions are related through

$k_{\mathrm{f}} / k_{\mathrm{r}}=f(B, m) \exp [\Delta E / k T]$,

where $f(B, m)$ is a factor that depends on the masses and partition functions of the reactants and products. The values of $\Delta E$ and $f(B, m)$ are taken from the work of THOO and are listed in Table A.2. At temperatures smaller than $\Delta E$, the forward reaction proceeds much faster than the backward reaction, thus shifting the steady-state abundances towards the reactants. In implementing the fractionation reactions of THOO in our network, we adopted a single Langevin rate of $10^{-9} \mathrm{~cm}^{3} \mathrm{~s}^{-1}$ for all forward reactions. The remaining reactions involving nitrogen atoms in our network have been duplicated to include their ${ }^{15} \mathrm{~N}$ homologue. The total number of species and reactions are 144 and 870 respectively. We do not consider freeze-out of any species in these models. We follow the time evolution of the chemical state of a parcel of gas of density $\left(n_{\mathrm{H}}=10^{4} \mathrm{~cm}^{-3}\right)$ and kinetic temperature of $10 \mathrm{~K}$, which was exposed to a cosmic-ray ionisation rate $\zeta=1.3 \times 10^{-17} \mathrm{~s}^{-1}$ and shielded from the ambient UV field by 20 mag of visual extinction, such that external UV photons do not play any significant role. However, secondary photons, which result from the fluorescence of $\mathrm{H}_{2}$ molecules excited by collisions with the electrons produced by cosmicrays are explicitly taken into account and are responsible for a significant fraction of the ionisation. The initial abundances are given in Table A.1, where an elemental isotopic ratio of nitrogen $\mathcal{R}_{0}=440$ was adopted (Marty et al. 2011).

\subsection{Chemical considerations}

The resulting abundances and abundance ratios of selected species are shown in Fig. 1. As is evident, all species reach a steady state after typically 5 Myrs, similar to what was found by Flower et al. (2006). This timescale is comparable to the lifetime of molecular clouds (Tassis \& Mouschovias 2004) but is larger than the free-fall timescale and slightly larger than the ambipolar diffusion one (e.g. Walmsley et al. 2004). Those dynamical timescales are mostly relevant for the inner and dense parts of dark clouds and are not directly applicable to the rather low density material modelled here. It is possible, but not certain, that the nitrogen-bearing species have reached steady-state. In any case, it must be recognized that the chemical timescale depends strongly on the initial abundances adopted.

In our calculations, the steady state is characterized by an $\mathrm{N}: \mathrm{N}_{2}$ abundance ratio close to unity, suggesting near equipartition between these two reservoir species. This is in sharp contrast to the calculations of Hily-Blant et al. (2010a), who found $\mathrm{N}_{2}$ to be 30-40 times more abundant than N. Unfortunately, the use of two different chemical networks, namely OSU 2009 in the latter case, impedes any direct comparison but undoubtedly calls for further investigation. Still, our predicted ratio is similar to that determined by Flower et al. (2006) with an older version of our chemical network. Another characteristic is the $\mathrm{HNC}: \mathrm{HCN} \approx 1$ ratio. We also see that $\mathrm{NH}_{3}$ is the most abundant of the three hydrides, with an abundance of $1.2 \times 10^{-8}$, when $\mathrm{NH}$ and $\mathrm{NH}_{2}$ have abundances of $5.1 \times 10^{-9}$ and $4.3 \times 10^{-9}$ respectively. The predicted abundance of ammonia is close to its value of $1.5-5.0 \times 10^{-8}$ in the cold envelope of IRAS 16293-2422. The latter estimate is a revision of the value published in Hily-Blant et al. (2010a). It is based on non-LTE radiative transfer calculations using the publicly available RATRAN and LIME codes, and taking into account all the observed ammonia lines, including the $572 \mathrm{GHz}$ fundamental line (Hogerheijde \& van der Tak 2000; Brinch \& Hogerheijde 2010). These calculations will be detailed elsewhere. There is also a good agreement for the abundances of $\mathrm{NH}$ and $\mathrm{NH}_{2}$. The predicted CN:HCN abundance ratio of 0.2 is smaller than the observed value, a discrepancy already noted by Hily-Blant et al. (2010b).

We now examine the predicted fractionation degree, that is, the enrichment or depletion in ${ }^{15} \mathrm{~N}$ with respect to the elemental ratio, of several nitrogen-bearing species, which is our main concern. The right panel of Fig. 1 shows the abundance ratios of nitrogen-bearing isotopologues as a function of time. Probably 

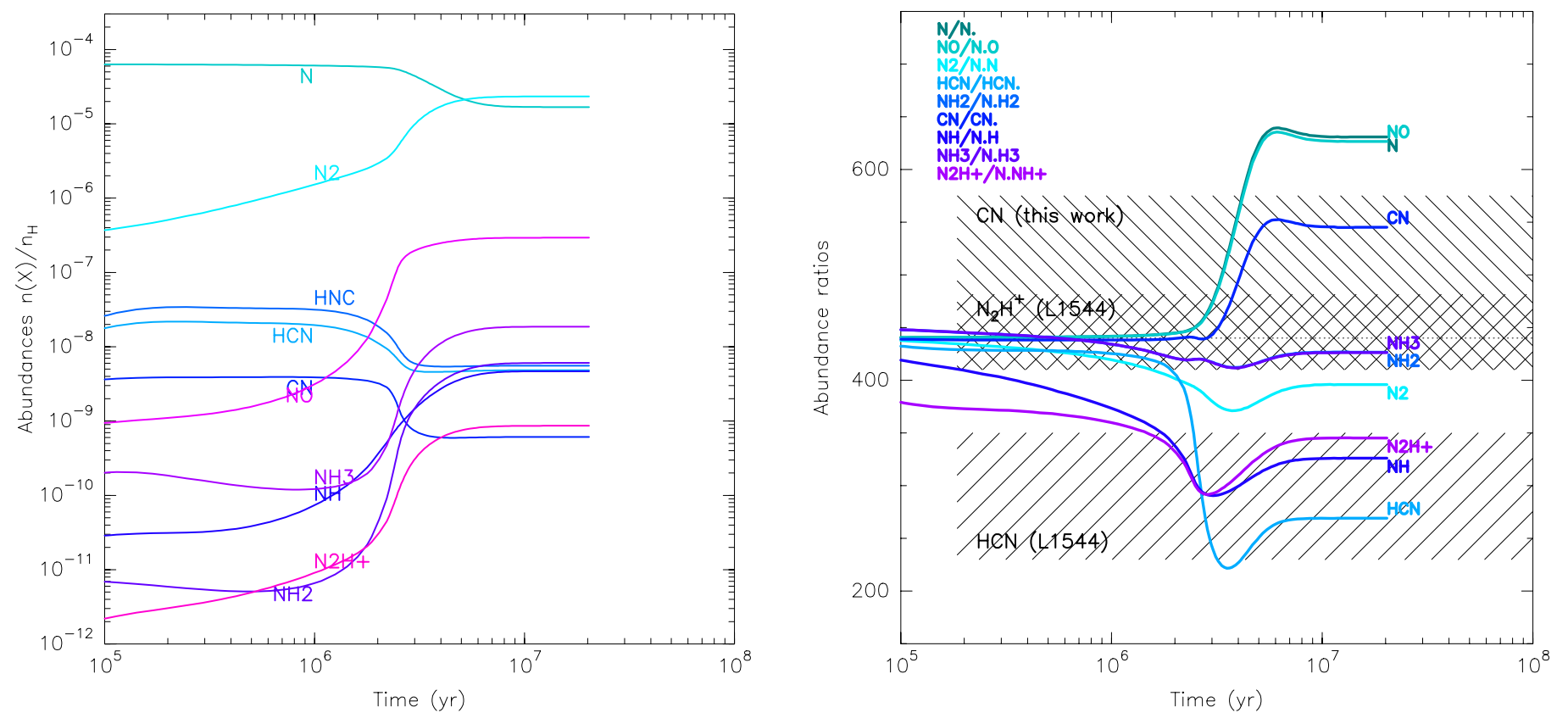

Fig. 1. Fractional abundances (left) and abundance ratios (right) of selected species. The observed isotopic ratios towards L1544 for HCN and CN, as well as towards $\mathrm{L} 1498$ for $\mathrm{CN}$, are shown as hatched areas (right panel). The ${ }^{15} \mathrm{~N}$ atom is noted N., such that CN. matches $\mathrm{C}^{15} \mathrm{~N}$, etc. The dotted line shows the adopted reference elemental isotopic ratio, ${ }^{14} \mathrm{~N} /{ }^{15} \mathrm{~N}=440$ (Marty et al. 2011).

the main result is that our model does predict large variations of the isotopic ratio in several species, contrary to the calculations of TH00, who found very small fractionation for all species. Our model predicts that the isotopic ratio of $\mathrm{N}$, which we note $\mathcal{R}(\mathrm{N})$, is $\approx 630$, and that $\mathcal{R}\left(\mathrm{N}_{2}\right) \approx 400$ (see Table 3). Since these species are also the reservoirs of nitrogen, this implies that most of the nitrogen is fractionated, either enriched or deprived in ${ }^{15} \mathrm{~N}$ and any enrichment/depletion of $\mathrm{N}$ in ${ }^{15} \mathrm{~N}$ implies depletion/enrichment of $\mathrm{N}_{2}$. Another striking feature is that until a few $10^{6}$ Myrs, isotopic ratios remain close to the initial value of 440. Beyond this time, three types of behaviour may be emphasized: species that are enriched in ${ }^{15} \mathrm{~N}$, those that are deprived in ${ }^{15} \mathrm{~N}$, and those that are not fractionated. The latter group includes $\mathrm{NH}_{2}$ and $\mathrm{NH}_{3}$. The positively fractionated molecules are $\mathrm{HCN}, \mathrm{HNC}$, and $\mathrm{NH}$, for which the steady-state isotopic ratio is $\approx 330$, and the depleted ones are N, NO, and CN. (see Table 3). The latter exhibits an isotopic ratio of $\approx 550$.

The depletion of atomic nitrogen in ${ }^{15} \mathrm{~N}$ is due to the fractionation reactions

${ }^{15} \mathrm{~N}+\mathrm{N}_{2} \mathrm{H}^{+} \longrightarrow{ }^{15} \mathrm{NNH}^{+}+\mathrm{N}$

and

$$
{ }^{15} \mathrm{~N}+\mathrm{N}_{2} \mathrm{H}^{+} \longrightarrow \mathrm{N}^{15} \mathrm{NH}^{+}+\mathrm{N}
$$

that are strongly favoured at low temperature with respect to the reverse process, due to a large $\Delta E=36 \mathrm{~K}$ (see Table A.2). The ratios predicted for $\mathrm{N}$ and $\mathrm{NO}$ are very close, and that of $\mathrm{CN}$, although smaller, follows the same trend. The former result is easily explained by recognizing that $\mathrm{NO}$ and ${ }^{15} \mathrm{NO}$ are produced and destroyed by the same two reactions:

$\mathrm{N}+\mathrm{OH} \stackrel{f_{1}}{\rightarrow} \mathrm{NO}+\mathrm{H}$

$\mathrm{NO}+\mathrm{N} \stackrel{d_{1}}{\longrightarrow} \mathrm{N}_{2}+\mathrm{O}$
For ${ }^{15} \mathrm{NO}$, the main formation channel is through reaction with ${ }^{15} \mathrm{~N}$, whilst the destruction channel is through reaction with $\mathrm{N}$. Hence the steady-state abundances of $\mathrm{NO}$ and ${ }^{15} \mathrm{NO}$ are given respectively by

$[\mathrm{NO}]=f_{1} / d_{1} \times[\mathrm{OH}]$

and

$\left[{ }^{15} \mathrm{NO}\right]=f_{1} / d_{1} \times\left[{ }^{15} \mathrm{~N}\right][\mathrm{OH}] /[\mathrm{N}]$,

leading to an isotopic ratio $\mathrm{NO} /{ }^{15} \mathrm{NO}=\mathrm{N} /{ }^{15} \mathrm{~N}$. The situation is similar for $\mathrm{CN}$, but as already noted, the isotopic ratio of $\mathrm{CN}$ is lower than that of $\mathrm{N}$ (and NO). This is because $\mathrm{C}_{2} \mathrm{~N}^{+}$and $\mathrm{H}_{2} \mathrm{CN}^{+}$are efficiently fractionated by the ion-neutral reactions of TH00 (see Table A.2), such that their isotopic ratios become smaller than $\mathcal{R}_{0}$. The dissociative recombination of these ions, which are normally negligible in producing $\mathrm{CN}$, contributes to about $10 \%$ to the formation of $\mathrm{C}^{15} \mathrm{~N}$. As a result, $\mathrm{C}^{15} \mathrm{~N}$ does not strictly follow the same behaviour as $\mathrm{N}$ and NO. Because $\mathrm{HCN}$ and HNC are primarily formed through the dissociative recombination of $\mathrm{H}_{2} \mathrm{CN}^{+}$, their isotopic ratios are similar to that of $\mathrm{H}_{2} \mathrm{CN}^{+}$.

We now turn our attention to nitrogen hydrides. To understand the different behaviour of $\mathrm{NH}$ on the one hand and $\mathrm{NH}_{2}$ and $\mathrm{NH}_{3}$ on the other hand, we first need to understand what determines the relative abundances of ${ }^{15} \mathrm{~N}^{+}$and $\mathrm{N}^{+}$. The $\mathrm{N}^{+}$ion is mostly produced by the reaction of $\mathrm{N}_{2}$ with $\mathrm{He}^{+}$. This is also true for ${ }^{15} \mathrm{~N}^{+}$, but the fractionation reaction

${ }^{15} \mathrm{~N}^{+}+\mathrm{N}_{2} \longrightarrow \mathrm{N}^{+}+\mathrm{N}^{15} \mathrm{~N}$

presents an exothermicity of $28 \mathrm{~K}$. The forward process leading to $\mathrm{N}^{15} \mathrm{~N}$ is therefore enhanced at low temperature with respect to the reverse process, and this is why $\mathcal{R}\left(\mathrm{N}_{2}\right)<\mathcal{R}\left(\mathrm{N}^{+}\right)$. As $\mathrm{N}_{2} \mathrm{H}^{+}$is a daughter molecule of $\mathrm{N}_{2}$, this also explains how 
Table 3. Steady-state abundances of selected species and their isotopologues (see also Fig. 1).

\begin{tabular}{lcccccc}
\hline \hline Species & {$[\mathrm{X}]^{a}$} & Species & {$[\mathrm{X}]^{a}$} & $\mathcal{R}^{b}$ & $\mathcal{R}_{n}{ }^{c}$ & $\delta_{15}{ }^{d}$ \\
\hline $\mathrm{N}$ & $1.7(-05)$ & ${ }^{15} \mathrm{~N}$ & $2.7(-08)$ & 631 & 1.4 & -569 \\
$\mathrm{~N}_{2}$ & $2.3(-05)$ & ${ }^{15} \mathrm{NN}$ & $1.2(-07)$ & 396 & 0.9 & -313 \\
$\mathrm{NO}$ & $2.9(-07)$ & ${ }^{15} \mathrm{NO}$ & $4.7(-10)$ & 627 & 1.4 & -566 \\
$\mathrm{CN}$ & $6.1(-10)$ & $\mathrm{C}^{15} \mathrm{~N}$ & $1.1(-12)$ & 545 & 1.2 & -501 \\
$\mathrm{HCN}$ & $4.8(-09)$ & $\mathrm{HC}^{15} \mathrm{~N}$ & $1.8(-11)$ & 269 & 0.6 & 11 \\
$\mathrm{NH}$ & $4.7(-09)$ & ${ }^{15} \mathrm{NH}^{15}$ & $1.4(-11)$ & 326 & 0.7 & -166 \\
$\mathrm{NH}_{2}$ & $6.1(-09)$ & ${ }^{15} \mathrm{NH}_{2}$ & $1.4(-11)$ & 427 & 1.0 & -363 \\
$\mathrm{NH}_{3}$ & $1.9(-08)$ & ${ }^{15} \mathrm{NH}_{3}$ & $4.4(-11)$ & 426 & 1.0 & -362 \\
$\mathrm{~N}_{2} \mathrm{H}^{+}$ & $8.6(-10)$ & ${ }^{15} \mathrm{NNH}^{+}$ & $2.5(-12)$ & 345 & 0.8 & -212 \\
& & $\mathrm{~N}^{15} \mathrm{NH}^{+}$ & $3.0(-12)$ & 292 & 0.7 & -69 \\
$\mathrm{~N}^{+}$ & $7.6(-11)$ & ${ }^{15} \mathrm{~N}^{+}$ & $1.5(-13)$ & 504 & 1.1 & -460 \\
$\mathrm{C}_{2} \mathrm{~N}^{+}$ & $8.8(-13)$ & $\mathrm{C}_{2}^{15} \mathrm{~N}^{+}$ & $3.3(-15)$ & 271 & 0.6 & 4 \\
$\mathrm{H}_{2} \mathrm{CN}^{+}$ & $9.6(-12)$ & $\mathrm{H}_{2} \mathrm{C}^{15} \mathrm{~N}^{+}$ & $3.8(-14)$ & 255 & 0.6 & 67 \\
$\mathrm{NH}^{+}$ & $4.4(-16)$ & ${ }^{15} \mathrm{NH}^{+}$ & $8.9(-19)$ & 497 & 1.1 & -453 \\
$\mathrm{NH}_{2}^{+}$ & $2.2(-15)$ & ${ }^{15} \mathrm{NH}_{2}^{+}$ & $4.8(-18)$ & 470 & 1.1 & -421 \\
$\mathrm{NH}_{3}^{+}$ & $4.5(-13)$ & ${ }^{15} \mathrm{NH}_{3}^{+}$ & $1.0(-15)$ & 439 & 1.0 & -381 \\
$\mathrm{NH}_{4}^{+}$ & $6.9(-12)$ & ${ }^{15} \mathrm{NH}_{4}^{+}$ & $1.6(-14)$ & 426 & 1.0 & -362 \\
\hline
\end{tabular}

Notes. ${ }^{(a)}$ Fractional abundance with respect to $n_{\mathrm{H}}$. Numbers in brackets are powers of ten. ${ }^{(b)}$ Abundance ratio of the two isotopologues: $n(\mathrm{XN}) / n\left(\mathrm{X}^{15} \mathrm{~N}\right)$. For species containing two nitrogen atoms, the ratio has been multiplied by two to emphasize that a ratio of 220 indeed means no fractionation for such species. ${ }^{(c)}$ Fractionation level, or normalized isotopic ratio, is the isotopic ratio normalized to the protosolar value ${ }^{14} \mathrm{~N} /{ }^{15} \mathrm{~N}=440$ from Marty et al. (2011). ${ }^{(d)}$ Depletion factor $\delta_{15}=1000 \times\left[\mathcal{R}_{\mathrm{ATM}} / \mathcal{R}-1\right]$, where the reference value $\mathcal{R}_{\mathrm{ATM}}=272$ is the isotopic ratio of the Earth atmosphere.

$\mathcal{R}\left(\mathrm{N}_{2} \mathrm{H}^{+}\right)<\mathcal{R}_{0}$, in addition to reactions (1)-(2). In turn, the enrichment of $\mathrm{N}_{2} \mathrm{H}^{+}$in ${ }^{15} \mathrm{~N}$ propagates into $\mathrm{NH}$ because, as Dislaire et al. (2012) have shown, the dissociative recombination of $\mathrm{N}_{2} \mathrm{H}^{+}$dominates the formation of $\mathrm{NH}$ over the $\mathrm{NH}_{2}^{+}+\mathrm{e}^{-}$channel. Therefore, we find that $\mathcal{R}(\mathrm{NH})<\mathcal{R}_{0}$. To explain how $\mathrm{NH}_{2}$ and $\mathrm{NH}_{3}$ behave differently, we recall that these two molecules result from the dissociative recombination of $\mathrm{NH}_{4}^{+}$, which itself results from successive hydrogen abstraction reactions initiated by $\mathrm{N}^{+}+\mathrm{H}_{2}$. The fractionation of $\mathrm{NH}_{2}$ and $\mathrm{NH}_{3}$ therefore reflects that of $\mathrm{N}^{+}$. Hence, $\mathcal{R}(\mathrm{NH})$ reflects that of $\mathrm{N}_{2}$, which is smaller than $\mathcal{R}_{0}$, whereas $\mathcal{R}\left(\mathrm{NH}_{2}\right)$ and $\mathcal{R}\left(\mathrm{NH}_{3}\right)$ reflect that of $\mathrm{N}^{+}$, which is larger than $\mathcal{R}_{0}$.

However, as is evident from Fig. 1 and Table $3, \mathcal{R}\left(\mathrm{NH}_{2}\right)$ and $\mathcal{R}\left(\mathrm{NH}_{3}\right)$ are not strictly equal to $\mathcal{R}\left(\mathrm{N}^{+}\right)$, as we would expect from the above reasoning. Indeed, the fractionation levels of $\mathrm{N}^{+}, \mathrm{NH}^{+}$, $\mathrm{NH}_{2}^{+}, \mathrm{NH}_{3}^{+}$, and $\mathrm{NH}_{4}^{+}$, are $480,470,450,434$, and 429 respectively. This shows that there is some enrichment in ${ }^{15} \mathrm{~N}$ at each step along the reaction chain which begins with $\mathrm{N}^{+}+\mathrm{H}_{2}$ and terminates with $\mathrm{NH}_{3}^{+}+\mathrm{H}_{2}$. The reason is that, because $\mathcal{R}(\mathrm{NH})>\mathcal{R}_{0}$, the reaction $\mathrm{H}^{+}+{ }^{15} \mathrm{NH}$ is faster than the similar reaction $\mathrm{H}^{+}+\mathrm{NH}$ and thus becomes non-negligible in the formation of ${ }^{15} \mathrm{NH}^{+}$. As a consequence, $\mathcal{R}\left(\mathrm{NH}^{+}\right)<\mathcal{R}\left(\mathrm{N}^{+}\right)$. In a similar fashion, the two reactions $\mathrm{H}_{3}^{+}+{ }^{15} \mathrm{NH}$ and $\mathrm{HCO}^{+}+{ }^{15} \mathrm{NH}$ contribute to the formation of ${ }^{15} \mathrm{NH}_{2}^{+}$, whereas their ${ }^{14} \mathrm{~N}$-homologues do not. This explains how the positive fractionation of $\mathrm{NH}$ propagates in the other two hydrides, though at a small level. Now, the next ions in the sequence, namely ${ }^{15} \mathrm{NH}_{3}^{+}$and ${ }^{15} \mathrm{NH}_{4}^{+}$, are further enriched in ${ }^{15} \mathrm{~N}$ with respect to $\mathrm{NH}_{2}^{+}$because ${ }^{15} \mathrm{NH}_{3}$ starts to contribute to their synthesis by reacting with $\mathrm{H}^{+}, \mathrm{H}_{3}^{+}$, and $\mathrm{C}^{+}$. In contrast, the ${ }^{14} \mathrm{~N}$-homologues of these reactions are negligible in forming $\mathrm{NH}_{3}$. As we see, minute variations of the isotopic ratio of a given species propagate into the chemical network because the increase in the relative abundance of the ${ }^{15} \mathrm{~N}$-isotopologue enhances reactions that are usually negligible, thus opening new formation paths.

Finally, the above chemical considerations may be summarized as follows. Atomic nitrogen is depleted in ${ }^{15} \mathrm{~N}$ with respect to $\mathrm{N}_{2}$ because of the fractionation reactions (1)-(2). Other reactions decrease $\mathcal{R}\left(\mathrm{H}_{2} \mathrm{CN}^{+}\right)$below $\mathcal{R}_{0}$, with the consequence that both $\mathcal{R}(\mathrm{HCN})$ and $\mathcal{R}(\mathrm{HNC})$ are lower than $\mathcal{R}_{0}$. Species that derive primarily from atomic nitrogen, like $\mathrm{NO}$ and $\mathrm{CN}$ (see e.g. $\mathrm{HB} 13)$, have isotopic ratios close to that of $\mathrm{N}$. Yet, for $\mathrm{CN}$, $\mathcal{R}\left(\mathrm{C}_{2} \mathrm{~N}^{+}\right)<\mathcal{R}_{0}$ drives $\mathcal{R}(\mathrm{CN})$ to values lower than $\mathcal{R}(\mathrm{N})$ and $\mathcal{R}(\mathrm{NO})$. Among hydrides, the positive fractionation of $\mathrm{NH}$ derives from that of $\mathrm{N}_{2} \mathrm{H}^{+}$, which is inherited from that of $\mathrm{N}_{2}$. In contrast, $\mathrm{NH}_{2}$ and $\mathrm{NH}_{3}$ are neither enriched nor depleted in ${ }^{15} \mathrm{~N}$ because they derive principally from $\mathrm{N}^{+}$, which is only very slightly fractionated.

Since the rate of the key reaction $\mathrm{N}^{+}+\mathrm{H}_{2}$ depends on the ortho:para ratio of $\mathrm{H}_{2}$, we performed a series of calculations with ortho:para ratios of $\mathrm{H}_{2}$ ranging from $10^{-6}$ to $10^{-3}$. The predicted isotopic ratios do not change by more than $10 \%$, except those of $\mathrm{NH}_{2}$ and $\mathrm{NH}_{3}$ which follow the same trend, decreasing from 427 to 305 when o:p is $10^{-3}$ and $10^{-6}$ respectively. In the process, the ratio of $\mathrm{NH}$ decreases only from 326 to 317 . The reason is that as o:p of $\mathrm{H}_{2}$ decreases, the rate of the reaction $\mathrm{N}^{+}+\mathrm{H}_{2}$ drops and the reaction $\mathrm{NH}+\mathrm{H}^{+}$starts to dominate the formation $\mathrm{NH}^{+}$and ${ }^{15} \mathrm{NH}^{+}$. This explains how the ratios of $\mathrm{NH}_{2}$ and $\mathrm{NH}_{3}$ become closer to that of $\mathrm{NH}$. Apart from this moderate change affecting $\mathrm{NH}_{2}$ and $\mathrm{NH}_{3}$, we conclude that the above results do not depend on the assumed value of o:p of $10^{-3}$.

\subsection{Comparisons to the observations}

The present model predictions are now compared to the $\mathrm{CN}$ and $\mathrm{HCN}$ isotopic ratios observed in L1544 and L1498 (right panel of Fig. 1). The isotopic ratio of $\mathrm{HCN}$ are $\mathcal{R}(\mathrm{HCN})=230-350$ and 190-280 towards the central positions of L1544 towards L183 respectively (HB13). This value is not available in the case of L1498. For CN, we take the values determined in Sect. 3. As is evident, the model predictions agree well with all the observational constraints. In particular, the isotopic ratios of $\mathrm{CN}$ and HCN estimated in L1544 are well reproduced by our model calculations.

More problematic is the case of $\mathrm{N}_{2} \mathrm{H}^{+}$. The constraints on $\mathrm{N}_{2} \mathrm{H}^{+} / \mathrm{N}^{15} \mathrm{NH}^{+}$from Bizzocchi et al. (2010), who found $446 \pm 71$, are plotted in Fig. 1. Our model predicts a significant enrichment for $\mathrm{N}^{15} \mathrm{NH}^{+}$, with $\mathcal{R}\left(\mathrm{N}_{2} \mathrm{H}^{+}\right)=280$. The fractionation of $\mathrm{N}^{15} \mathrm{NH}^{+}$is associated with the reaction of $\mathrm{N}_{2} \mathrm{H}^{+}$with ${ }^{15} \mathrm{~N}$. From Table 3, we note that the fractionation of $\mathrm{N}^{15} \mathrm{NH}^{+}$is larger than that of ${ }^{15} \mathrm{NNH}^{+}$, a result of the different zero-point energy differences of the two reactions

$\mathrm{N}_{2}+\mathrm{N}^{15} \mathrm{NH}^{+} \longrightarrow{ }^{15} \mathrm{NN}+\mathrm{N}_{2} \mathrm{H}^{+}$

and

$\mathrm{N}_{2}+{ }^{15} \mathrm{NNH}^{+} \longrightarrow{ }^{15} \mathrm{NN}+\mathrm{N}_{2} \mathrm{H}^{+}$

whose exothermicities are respectively $\Delta E=10.7$ and $2.25 \mathrm{~K}$. These reactions may proceed either by breaking an N-H bond 
or an $\mathrm{N}-\mathrm{N}$ bond. In the latter case, the reaction likely requires a strong activation energy. If we artificially switch off these two reactions, we note that the fractionations of ${ }^{15} \mathrm{NNH}^{+}$and $\mathrm{N}^{15} \mathrm{NH}^{+}$ become equal, as expected, with a isotopic ratio of 340 . Yet, this value is only slightly larger than the value in Table 3 and is still outside the permitted value from Bizzocchi et al. (2010) by a small factor. The same argument may apply even more likely to the fractionation reactions $\mathrm{N}+\mathrm{N}_{2} \mathrm{H}^{+}$, which proceeds through $\mathrm{N}-\mathrm{N}$ bond breaking. Suppressing the latter reactions has a much stronger effect on the fractionation picture because these reactions are responsible for the fractionation of atomic nitrogen (see the discussion above). In particular, NH becomes less fractionated and $\mathrm{CN}$ and $\mathrm{N}_{2} \mathrm{H}^{+}$have similar isotopic ratios $\approx 400$, whereas HCN fractionation remains unaffected. This further illustrates the dichotomy suggested by HB13. Observations of ${ }^{15} \mathrm{NNH}^{+}$would enable the first suggestion to be tested.

The models presented here have a $\mathrm{C} / \mathrm{O}$ abundance ratio of 0.50 , which falls in between the low-metal-abundance value of 0.41 from Wakelam \& Herbst (2008) and the value of 0.67 from Flower \& Pineau des Forêts (2003). We also performed model calculations with $\mathrm{C} / \mathrm{O}=0.40$, for which all the above reasoning applies equally, though predicting a smaller $\mathcal{R}(\mathrm{CN})$ whilst maintaining a fractionation of $\mathrm{HCN}$ close to the case $\mathrm{C} / \mathrm{O}=0.50$. We thus found a better agreement with the calculations having $\mathrm{C} / \mathrm{O}=0.50$. Exploring the effects of the initial abundances is an important area of investigation. However, it is beyond the scope of the present work and is deferred to a subsequent paper.

\section{Conclusions and perspectives}

Combining observations of $\mathrm{C}^{15} \mathrm{~N}$ and ${ }^{13} \mathrm{CN}$ and assuming a $\mathrm{CN}:{ }^{13} \mathrm{CN}$ isotopic ratio, we have estimated the $\mathrm{CN}: \mathrm{C}^{15} \mathrm{~N}$ ratio towards two dark clouds. In both cases, the $\mathrm{CN}$ molecule appears slightly depleted in ${ }^{15} \mathrm{~N}$ with respect to the solar wind elemental ratio, with a $\mathrm{CN}: \mathrm{C}^{15} \mathrm{~N}$ ratio $\approx 500 \pm 75$ or depletion values $\delta_{15}=[272 / \mathcal{R}(\mathrm{CN})-1]=-527$ to $-360 \%$. Towards L1544, additional constraints are provided by the $\mathrm{HCN}: \mathrm{HC}^{15} \mathrm{~N}$ ratio. We performed chemical model calculations, which include ion-neutral fractionation reactions for nitrogen-bearing species. Our gas-phase model predicts significant fractionation of many species. This is in sharp contrast to the former predictions of Terzieva \& Herbst (2000). Even though the model of Charnley \& Rodgers (2002) also produces fractionation of nitrogen-bearing species, the comparison with our calculations is not direct because the freeze-out of $\mathrm{CO}$ onto dust particles is a prerequisite to fractionation in their calculations. In contrast, we note that our model calculations predict fractionation without the need for depletion. Quite interestingly, our model is able to reproduce simultaneously ${ }^{15} \mathrm{~N}$-poor $\mathrm{CN}$ and ${ }^{15} \mathrm{~N}$-rich $\mathrm{HCN}$, as is observed towards L1544. This indeed also demonstrates that these two observational facts do not contradict the chemical argument of HB13, according to which there are two families of nitrogenated species, namely nitriles, and hydrides, which present different sensitivity to fractionation. However, the present work allowed us to explore the mechanisms responsible for the differential fractionation among nitrogenated species and, in particular, to understand how $\mathrm{CN}$ can be slightly depleted in ${ }^{15} \mathrm{~N}$ and at the same time $\mathrm{HCN}$ be enriched in ${ }^{15} \mathrm{~N}$. The differential fractionation of $\mathrm{CN}$ and $\mathrm{HCN}$ is at odds with observations in comets (Bockelée-Morvan et al. 2008; Manfroid et al. 2009), where similar isotopic ratios are obtained for both species. These two observational facts could be reconciled by assuming that $\mathrm{CN}$ is a daughter molecule of HCN (e.g. by photolysis) (for a discussion, see e.g. Mumma \& Charnley 2011). Another limitation in our model is brought to light by the isotopic ratios of $\mathrm{N}_{2} \mathrm{H}^{+} / \mathrm{N}^{15} \mathrm{NH}^{+}$ and $\mathrm{N}_{2} \mathrm{H}^{+} /{ }^{15} \mathrm{NNH}^{+}$which are predicted below 380 , whilst observationally the former is $461 \pm 71$. We suggest that observations of ${ }^{15} \mathrm{NNH}^{+}$would bring strong constraints on the fractionation processes at work. In particular, whether these two ratios are equal or different would suggest that some of the underlying fractionation reactions present large activation energy. Another possibility, not considered in this work, is that depletion of gas-phase elements, (in particular $\mathrm{CO}$, which is a predator of $\mathrm{N}_{2} \mathrm{H}^{+}$) plays a significant role for the fractionation of $\mathrm{N}_{2} \mathrm{H}^{+}$. On more general grounds, the present calculations suggest that a thorough comparison of the Ohio State University (OSU) chemical network with the one used here will potentially provide insights to the chemical processes at work.

From an astrochemical point of view, observations of as many species as possible is most welcome. However, $\mathrm{C}^{15} \mathrm{~N}$ detection is time demanding, and further progress may rather benefit from observations of $\mathrm{HC}^{15} \mathrm{~N}$ and $\mathrm{H}^{15} \mathrm{NC}$ towards a larger sample of sources. In addition, observations of ${ }^{15} \mathrm{NH}_{3}$ would bring extremely interesting constraints, but the discrepancy between the results of Lis et al. (2010) and Gerin et al. (2009) suggests that the interpretation of such observations may not be straightforward. Observations of ${ }^{15} \mathrm{NO}$ would also be most valuable. However, this molecule presents both fine and hyperfine splittings such that the intensity may be diluted within too many components, making this species particularly difficult to detect. The hypothesis of Hily-Blant et al. (2013) could also be pushed forward by observing isotopologues of more complex nitriles, such as $\mathrm{HC}_{3} \mathrm{~N}$ and beyond.

Acknowledgements. We acknowledge the comments of the anonymous referee, which helped to improve the scientific quality of the manuscript. Funding for this project was provided by grants from la Région Rhône-Alpes and from the Physico-Chimie du Milieu Interstellaire program. R.L.G. helds a doctoral fellowship from la Région Rhône-Alpes.

\section{References}

Adande, G. R., \& Ziurys, L. M. 2012, ApJ, 744-758, 194 Asplund, M., Grevesse, N., Sauval, A. J., \& Scott, P. 2009, ARA\&A, 47, 481 Bizzocchi, L., Caselli, P., \& Dore, L. 2010, A\&A, 510, L5

Bockelée-Morvan, D., Biver, N., Jehin, E., et al. 2008, ApJ, 679, L49

Bogey, M., Demuynck, C., \& Destombes, J. L. 1984, Can. J. Phys., 62, 1248

Bonal, L., Huss, G. R., Krot, A. N., et al. 2010, Geochim. Cosmochim Acta, 74 6590

Brinch, C., \& Hogerheijde, M. R. 2010, A\&A, 523, A25

Carter, M., Lazareff, B., Maier, D., et al. 2012, A\&A, 538, A89

Caselli, P., Keto, E., Bergin, E. A., et al. 2012, ApJ, 759, L37

Charnley, S. B., \& Rodgers, S. D. 2002, ApJ, 569, L133

Chaussidon, M., \& Gounelle, M. 2007, Comptes Rendus Geoscience, 339, 872

Crapsi, A., Caselli, P., Walmsley, C. M., et al. 2005, ApJ, 619, 379

Crapsi, A., Caselli, P., Walmsley, M. C., \& Tafalla, M. 2007, A\&A, 470, 221

Daranlot, J., Hincelin, U., Bergeat, A., et al. 2012, PNAS, 109, 10233

Dislaire, V., Hily-Blant, P., Faure, A., et al. 2012, A\&A, 537, A20

Dutrey, A., Guilloteau, S., \& Guélin, M. 1997, A\&A, 317, L55

Dutrey, A., Henning, T., Guilloteau, S., et al. 2007, A\&A, 464, 615

Elsila, J. E., Glavin, D. P., \& Dworkin, J. P. 2009, Meteorit. Planet. Sci., 44, 1323

Faure, A., \& Lique, F. 2012, MNRAS, 425, 740

Flower, D. R., \& Pineau des Forêts, G. 2003, MNRAS, 343, 390

Flower, D. R., Pineau des Forêts, G., \& Walmsley, C. M. 2006, A\&A, 456, 215

Gerin, M., Viala, Y., Pauzat, F., \& Ellinger, Y. 1992, A\&A, 266, 463

Gerin, M., Marcelino, N., Biver, N., et al. 2009, A\&A, 498, L9

Hily-Blant, P., Pety, J., \& Guilloteau, S. 2005, CLASS evolution: I. Improved OTF support, Tech. rep., IRAM

Hily-Blant, P., Walmsley, M., Pineau des Forêts, G., \& Flower, D. 2008, A\&A, 480, L5

Hily-Blant, P., Maret, S., Bacmann, A., et al. 2010a, A\&A, 521, L52

Hily-Blant, P., Walmsley, M., Pineau des Forêts, G., \& Flower, D. 2010b, A\&A,

513, A41

Hily-Blant, P., Bonal, L., Faure, A., \& Quirico, E. 2013, Icarus, 223, 582 
Hogerheijde, M. R., \& van der Tak, F. F. S. 2000, A\&A, 362, 697

Ikeda, M., Hirota, T., \& Yamamoto, S. 2002, ApJ, 575, 250

Jehin, E., Manfroid, J., Hutsemékers, D., Arpigny, C., \& Zucconi, J.-M. 2009, Earth Moon and Planets, 105, 167

Kalugina, Y., Lique, F., \& Kłos, J. 2012, MNRAS, 422, 812

Kastner, J. H., Hily-Blant, P., Sacco, G. G., Forveille, T., \& Zuckerman, B. 2010, ApJ, 723, L248

Langer, W. D., Graedel, T. E., Frerking, M. A., \& Armentrout, P. B. 1984, ApJ, 277,581

Lis, D. C., Wootten, A., Gerin, M., \& Roueff, E. 2010, ApJ, 710, L49

Lucas, R., \& Liszt, H. 1998, A\&A, 337, 246

Manfroid, J., Jehin, E., Hutsemékers, D., et al. 2009, A\&A, 503, 613

Marty, B., Chaussidon, M., Wiens, R. C., Jurewicz, A. J. G., \& Burnett, D. S. 2011, Science, 332, 1533

Milam, S. N., Savage, C., Brewster, M. A., Ziurys, L. M., \& Wyckoff, S. 2005, ApJ, 634, 1126

Müller, H. S. P., Schlöder, F., Stutzki, J., \& Winnewisser, G. 2005, J. Mol. Struct., 742,215
Mumma, M. J., \& Charnley, S. B. 2011, Annu. Rev. Astron. Astrophys., 49, 471 Neufeld, D. A., \& Green, S. 1994, ApJ, 432, 158

Padovani, M., Walmsley, C. M., Tafalla, M., Hily-Blant, P., \& Pineau des Forêts, G. 2011, A\&A, 534, A77

Pety, J. 2005, in SF2A-2005: Semaine de l'Astrophysique Francaise, eds. F. Casoli, T. Contini, J. M. Hameury, \& L. Pagani, 721 (EDP Science)

Rist, C., Faure, A., Hily-Blant, P., \& Le Gal, R. 2013, J. Phys. Chem. A, in press Saleck, A. H., Simon, R., \& Winnewisser, G. 1994, ApJ, 436, 176

Tassis, K., \& Mouschovias, T. C. 2004, ApJ, 616, 283

Terzieva, R., \& Herbst, E. 2000, MNRAS, 317, 563

van der Tak, F. F. S., Black, J. H., Schöier, F. L., Jansen, D. J., \& van Dishoeck, E. F. 2007, A\&A, 468, 627

Vigren, E., Zhaunerchyk, V., Hamberg, M., et al. 2012, ApJ, 757, 34

Wakelam, V., \& Herbst, E. 2008, ApJ, 680, 371

Walmsley, C. M., Flower, D. R., \& Pineau des Forêts, G. 2004, A\&A, 418, 1035

Watson, W. D., Anicich, V. G., \& Huntress, W. T. 1976, ApJ, 205, L165

Wilson, T. L., \& Rood, R. 1994, Annu. Rev. Astron. Astrophys., 32, 191 
Table A.1. Elemental abundances (taken from Flower \& Pineau des Forêts 2003), except for O. Numbers in parentheses are powers of 10.

\begin{tabular}{lc}
\hline \hline Species & $n(\mathrm{X}) / n_{\mathrm{H}}$ \\
\hline $\mathrm{He}$ & 0.1 \\
$\mathrm{~N}$ & $6.4(-5)$ \\
${ }^{15} \mathrm{~N}$ & $1.5(-7)$ \\
$\mathrm{O}$ & $2.1(-4)$ \\
$\mathrm{C}^{+}$ & $8.3(-5)$ \\
$\mathrm{S}^{+}$ & $1.9(-6)$ \\
$\mathrm{Fe}^{+}$ & $3.0(-9)$ \\
\hline
\end{tabular}

Notes. $n_{\mathrm{H}}=n(\mathrm{H})+2 n\left(\mathrm{H}_{2}\right)$.

Table A.2. Fractionation reactions and rate coefficients $(k(T)=$ $\left.\alpha(T / 300)^{\beta} \exp (-\Delta E / T) \mathrm{cm}^{3} \mathrm{~s}^{-1}\right)$ implemented in our chemical network (from TH00).

\begin{tabular}{|c|c|c|c|c|}
\hline Reaction & $\begin{array}{c}\alpha \\
10^{-9} \mathrm{~cm}^{3} \mathrm{~s}^{-1} \\
\end{array}$ & $\beta$ & $\begin{array}{c}\Delta E \\
\mathrm{~K}\end{array}$ & $\begin{array}{l}k(10 \mathrm{~K}) \\
\mathrm{cm}^{3} \mathrm{~s}^{-1}\end{array}$ \\
\hline${ }^{15} \mathrm{NN}+\mathrm{N}_{2} \mathrm{H}^{+} \longrightarrow \mathrm{N}_{2}+\mathrm{N}^{15} \mathrm{NH}^{+}$ & 1.0 & 0.0 & 0.0 & $1.0(-09)$ \\
\hline $\mathrm{N}_{2}+\mathrm{N}^{15} \mathrm{NH}^{+} \longrightarrow{ }^{15} \mathrm{NN}+\mathrm{N}_{2} \mathrm{H}^{+}$ & 2.0 & 0.0 & 10.7 & $6.9(-10)$ \\
\hline${ }^{15} \mathrm{NN}+\mathrm{N}_{2} \mathrm{H}^{+} \longrightarrow \mathrm{N}_{2}+{ }^{15} \mathrm{NNH}^{+}$ & 1.0 & 0.0 & 0.0 & $1.0(-09)$ \\
\hline $\mathrm{N}_{2}+{ }^{15} \mathrm{NNH}^{+} \longrightarrow{ }^{15} \mathrm{NN}+\mathrm{N}_{2} \mathrm{H}^{+}$ & 2.0 & 0.0 & 2.3 & $1.6(-09)$ \\
\hline${ }^{15} \mathrm{~N}+\mathrm{N}_{2} \mathrm{H}^{+} \longrightarrow{ }^{15} \mathrm{NNH}^{+}+\mathrm{N}$ & 1.0 & 0.0 & 0.0 & $1.0(-09)$ \\
\hline $\mathrm{N}+{ }^{15} \mathrm{NNH}^{+} \longrightarrow{ }^{15} \mathrm{~N}+\mathrm{N}_{2} \mathrm{H}^{+}$ & 1.0 & 0.0 & 36.1 & $2.7(-11)$ \\
\hline${ }^{15} \mathrm{~N}+\mathrm{N}_{2} \mathrm{H}^{+} \longrightarrow \mathrm{N}^{15} \mathrm{NH}^{+}+\mathrm{N}$ & 1.0 & 0.0 & 0.0 & $1.0(-09)$ \\
\hline $\mathrm{N}+\mathrm{N}^{15} \mathrm{NH}^{+} \longrightarrow{ }^{15} \mathrm{~N}+\mathrm{N}_{2} \mathrm{H}^{+}$ & 1.0 & 0.0 & 27.7 & $6.3(-11)$ \\
\hline${ }^{15} \mathrm{~N}^{+}+\mathrm{N}_{2} \longrightarrow \mathrm{N}^{+}+{ }^{15} \mathrm{NN}$ & 1.0 & 0.0 & 0.0 & $1.0(-09)$ \\
\hline $\mathrm{N}^{+}+{ }^{15} \mathrm{NN} \longrightarrow{ }^{15} \mathrm{~N}^{+}+\mathrm{N}_{2}$ & 0.5 & 0.0 & 28.3 & $3.0(-11)$ \\
\hline${ }^{15} \mathrm{~N}^{+}+\mathrm{NO} \longrightarrow \mathrm{N}^{+}+{ }^{15} \mathrm{NO}$ & 1.0 & 0.0 & 0.0 & $1.0(-09)$ \\
\hline $\mathrm{N}^{+}+{ }^{15} \mathrm{NO} \longrightarrow{ }^{15} \mathrm{~N}^{+}+\mathrm{NO}$ & 1.0 & 0.0 & 24.3 & $8.8(-11)$ \\
\hline${ }^{15} \mathrm{~N}+\mathrm{H}_{2} \mathrm{CN}^{+} \longrightarrow \mathrm{N}+\mathrm{H}_{2} \mathrm{C}^{15} \mathrm{~N}^{+}$ & 1.0 & 0.0 & 0.0 & $1.0(-09)$ \\
\hline $\mathrm{N}+\mathrm{H}_{2} \mathrm{C}^{15} \mathrm{~N}^{+} \longrightarrow{ }^{15} \mathrm{~N}+\mathrm{H}_{2} \mathrm{CN}^{+}$ & 1.0 & 0.0 & 35.9 & $2.8(-11)$ \\
\hline${ }^{15} \mathrm{~N}+\mathrm{H}_{2} \mathrm{NC}^{+} \longrightarrow \mathrm{N}+\mathrm{H}_{2}{ }^{15} \mathrm{NC}^{+}$ & 1.0 & 0.0 & 0.0 & $1.0(-09)$ \\
\hline $\mathrm{N}+\mathrm{H}_{2}{ }^{15} \mathrm{NC}^{+} \longrightarrow{ }^{15} \mathrm{~N}+\mathrm{H}_{2} \mathrm{NC}^{+}$ & 1.0 & 0.0 & 35.9 & $2.8(-11)$ \\
\hline
\end{tabular}

\section{Appendix A: Chemical model}

We implemented the fractionation reactions of TH00, assuming a symmetry factor $f(B, m)$ of unity for all reactions, unless $\mathrm{N}_{2}$ appears as a reactant or as a product. In these cases, $f(B, m)=0.5$ or 1 respectively. A constant Langevin rate of $10^{-9} \mathrm{~cm}^{3} \mathrm{~s}^{-1}$ was adopted for these ion-neutral reactions. The zero-point energy differences are taken from TH00. The reactions and their rate coefficients are listed in Table A.2.

\section{Appendix B: Collisional rate coefficients}

The hyperfine rate coefficients for ${ }^{13} \mathrm{CN}+\mathrm{H}_{2}$ and $\mathrm{C}^{15} \mathrm{~N}+\mathrm{H}_{2}$ were derived from the fine-structure rate coefficients computed by Kalugina et al. (2012) for $\mathrm{CN}+\mathrm{H}_{2}$. The latter coefficients were determined from fully quantum close-coupling (CC) calculations based on a highly correlated potential energy surface. Rate coefficients were deduced for temperatures ranging from 5 to 100 K. Full details can be found in Kalugina et al. (2012).
The ${ }^{13} \mathrm{C}$ (with nuclear spin $\left.I=1 / 2\right)$ and ${ }^{15} \mathrm{~N}(I=1 / 2)$ substitutions in $\mathrm{CN}$ (in which ${ }^{14} \mathrm{~N}$ has a nuclear spin $I=1$ ) significantly modify the hyperfine structure of the molecule. Yet, the fine-structure rate coefficients can be considered nearly identical for the three isotopologues. To derive the ${ }^{13} \mathrm{CN}$ and $\mathrm{C}^{15} \mathrm{~N}$ hyperfine rate coefficients, we used the infinite-order-sudden (IOS) approximation applied to the $\mathrm{CN}$ fine-structure rate coefficients of Kalugina et al. (2012). Within this approximation, where the fine-structure energy spacings are ignored compared to the collision energy, the rate coefficients between fine-structure levels $\left(k_{N j \rightarrow N^{\prime} j^{\prime}}(T)\right.$ for a ${ }^{2} \Sigma$ state molecule) can be obtained directly from the "fundamental" fine-structure rate coefficients (those out of the lowest $N=0$ level) as follows:

$$
\begin{aligned}
k_{N j \rightarrow N^{\prime} j^{\prime}}^{I O S}(T)= & \left(2 j^{\prime}+1\right) \sum_{L} \frac{2 L+1}{L+1}\left(\begin{array}{ccc}
j^{\prime} & L & j \\
-1 / 2 & 0 & 1 / 2
\end{array}\right)^{2} \\
& \times \frac{1}{2}\left[1-\epsilon(-1)^{j+j^{\prime}+L}\right] k_{0,1 / 2 \rightarrow L, L+1 / 2}^{I O S}(T),
\end{aligned}
$$

where $\epsilon$ is equal to +1 if the parity of initial and final rotational $N j$ level is the same or -1 if the parity of initial and final rotational $\mathrm{Nj}$ level differ ${ }^{1}$.

For $\mathrm{C}^{15} \mathrm{~N}$, which possesses a single non-zero nuclear spin, the IOS rate coefficients among hyperfine-structure levels can be obtained from the $k_{0,1 / 2 \rightarrow L, L+1 / 2}^{I O S}(T)$ rate coefficients as

$$
\begin{aligned}
& k_{N j F \rightarrow N^{\prime} j^{\prime} F^{\prime}}^{I O S}(T)=(2 j+1)\left(2 j^{\prime}+1\right)\left(2 F^{\prime}+1\right) \sum_{L} \frac{2 L+1}{L+1} \\
& \times\left(\begin{array}{ccc}
j^{\prime} & L & j \\
-1 / 2 & 0 & 1 / 2
\end{array}\right)^{2}\left\{\begin{array}{ccc}
j & j^{\prime} & L \\
F^{\prime} & F & I
\end{array}\right\}^{2} \\
& \times \frac{1}{2}\left[1+\epsilon(-1)^{j+j^{\prime}+L}\right] k_{0,1 / 2 \rightarrow L, L+1 / 2}^{I O S}(T),
\end{aligned}
$$

where $I=1 / 2$ is the nuclear-spin of ${ }^{15} \mathrm{~N}$. In practice, the $\mathrm{CN}$ fine-structure energy spacings are not negligibly small and the IOS approximation is expected to fail at low temperature $(T<$ $100 \mathrm{~K})$. However, since it correctly predicts the relative rates among hyperfine levels (because the propensity rules are properly included through the Wigner coefficients), a simple method to correct the low temperature results is to scale the IOS results, as originally suggested by Neufeld \& Green (1994):

$k_{N j F \rightarrow N^{\prime} j^{\prime} F^{\prime}}^{I N F}(T)=\frac{k_{N j F \rightarrow N^{\prime} j^{\prime} F^{\prime}}^{I O S}(T)}{k_{N j \rightarrow N^{\prime} j^{\prime}}^{I O S}(T)} k_{N j \rightarrow N^{\prime} j^{\prime}}^{C C}(T)$.

In this approach the $\mathrm{CC}$ rate coefficients $k^{C C}(0,1 / 2 \rightarrow L, L+$ $1 / 2$ ) must be employed as the IOS fundamental rates in both Eqs. (B.1) and (B.2). The scaling procedure thus ensures that

$\sum_{F^{\prime}} k_{N j F \rightarrow N^{\prime} j^{\prime} F^{\prime}}^{I N F}(T)=k_{N j \rightarrow N^{\prime} j^{\prime}}^{C C}(T)$.

It should be noted that the propensity rule $\Delta j=\Delta F$ predicted by the recoupling approach is also properly reproduced by IOS approximation, as discussed in Faure \& Lique (2012). We note that for $\mathrm{CN}$ there is also a strong propensity for transitions with even $\Delta N$ Kalugina et al. (2012). In practice, the first 22 hyperfine levels of $\mathrm{C}^{15} \mathrm{~N}$ were considered, corresponding to rate coefficients for all 210 transitions among levels with $N \leq 5$.

\footnotetext{
1 Note that there is a typo regarding the sign of $\epsilon$ in Eq. (7) of Faure \& Lique (2012).
} 

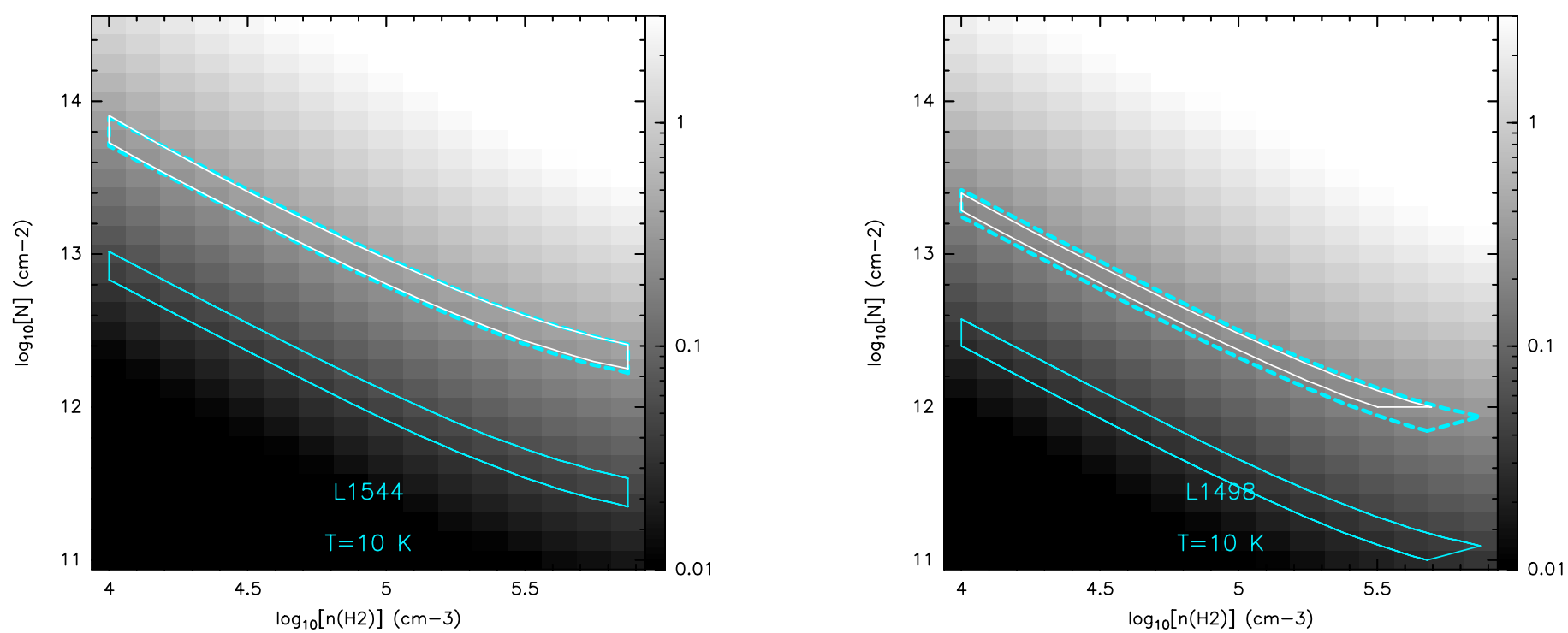

Fig. B.1. LVG predictions at $T=10 \mathrm{~K}$ towards L1544 (left) and L1498 (right). In each panel, the grey scale shows the predicted intensity of the $110024.590 \mathrm{MHz}$ component of the $\mathrm{C}^{15} \mathrm{~N}(1-0)$ hyperfine multiplet. The boxes (full line) delineate the solutions for the $\mathrm{C}^{15} \mathrm{~N}$ (cyan) and the ${ }^{13} \mathrm{CN}$ lines (white). The dashed box shows the $\mathrm{C}^{15} \mathrm{~N}$ solutions when the $\mathrm{C}^{15} \mathrm{~N}$ column density is multiplied by factors of 7.5 and 7 for L1544 and L1498 respectively.

For ${ }^{13} \mathrm{CN}$, which possesses two non-zero nuclear spins, the IOS rate coefficients among hyperfine structure levels can be obtained similarly, including an additional coupling:

$$
\begin{aligned}
& k_{N j F_{1} F \rightarrow N^{\prime} j^{\prime} F_{1}^{\prime} F^{\prime}}^{I O S}(T)=(2 j+1)\left(2 j^{\prime}+1\right)\left(2 F_{1}+1\right)\left(2 F_{1}^{\prime}+1\right)\left(2 F^{\prime}+1\right) \\
& \times \sum_{L} \frac{2 L+1}{L+1}\left(\begin{array}{ccc}
j^{\prime} & L & j \\
-1 / 2 & 0 & 1 / 2
\end{array}\right)^{2}\left\{\begin{array}{ccc}
j & j^{\prime} & L \\
F_{1}^{\prime} & F_{1} & I_{1}
\end{array}\right\}^{2}\left\{\begin{array}{ccc}
j & j^{\prime} & L \\
F^{\prime} & F & I_{2}
\end{array}\right\}^{2} \\
& \times \frac{1}{2}\left[1-\epsilon(-1)^{j+j^{\prime}+L}\right] k_{0,1 / 2 \rightarrow L, L+1 / 2}^{I O S}(T),
\end{aligned}
$$

where $I_{1}=1 / 2$ and $I_{2}=1$ are the nuclear spins of ${ }^{13} \mathrm{C}$ and ${ }^{14} \mathrm{~N}$ respectively. The propensity rule is in this case $\Delta j=\Delta F_{1}=\Delta F$ and the scaling formula writes

$k_{N j F_{1} F \rightarrow N^{\prime} j^{\prime} F_{1}^{\prime} F^{\prime}}^{I N F}(T)=\frac{k_{N j F_{1} F \rightarrow N^{\prime} j^{\prime} F_{1}^{\prime} F^{\prime}}^{I O S}(T)}{k_{N j \rightarrow N^{\prime} j^{\prime}}^{I O S}(T)} k_{N j \rightarrow N^{\prime} j^{\prime}}^{C C}(T)$.

In practice, the first 62 hyperfine levels of ${ }^{13} \mathrm{CN}$ were considered, corresponding to rate coefficients for all 1676 transitions among levels with $N \leq 5$. 